Working Paper 10-20

Economic Series 08

September 2010
Departamento de Economía Universidad Carlos III de Madrid

Calle Madrid, 126

28903 Getafe (Spain)

Fax (34) 916249875

\title{
The Welfare Effects of Location and Quality in Oligopoly
}

\author{
Luis C. Corchón, Galina Zudenkova*
}

Department of Economics, Universidad Carlos III de Madrid ${ }^{\dagger}$

First Draft: November 19th, 2007. This draft: September 7th, 2010

\begin{abstract}
In this paper we argue that two important causes of welfare losses in oligopolistic markets have been neglected. We show that in models where location is endogenous, welfare losses arising from wrong locations or from lack of market coverage may be substantial despite firms competing in prices. In contrast, welfare losses arising from quality choice are modest but they might vary discontinuously with the size of the market.
\end{abstract}

JEL classification: D61; L11; L13; L50.

Keywords: Welfare losses; Horizontal differentiation; Hotelling model; Salop model; Vertical differentiation.

* We thank Nicholas Economides, Ying Fan and seminar and conference participants at the Center of Applied Economics (Universidad de Chile) and EUNIP International Conference (Reus) for very helpful comments. The first author acknowledges financial support from SEJ2005-06167/ECON. The second author acknowledges financial support from BES-2005-10017.

† Corresponding author. Department of Economics, Universidad Carlos III de Madrid, c/ Madrid 126, Getafe (Madrid) 28903, Spain. E-mail address: galina.zudenkova@gmail.com. 


\section{Introduction}

An important issue in Industrial Organization is the study of the inefficiencies yielded by imperfect competition. In a pathbreaking contribution, Harberger (1954) provided a quantitative estimate of these inefficiencies by computing the "Harberger triangle" for a number of US manufacturing industries. Later studies disputed the findings of Harberger. In particular, several authors pointed out other sources of welfare losses, such as lack of cost minimization (Leibenstein 1966) or the expenses of acquiring/maintaining market power (Tullock 1967). ${ }^{1}$

In this paper we aim to contribute to this line of thinking. We will argue that several crucial determinants of welfare losses have been neglected and others may have been overstated. To substantiate our point, we study welfare losses in models of horizontal differentiation (Hotelling 1929, d'Aspremont, Gabszewicz and Thisse 1979, Economides 1984 and Salop 1979) and vertical differentiation (Gabszewicz and Thisse 1979, 1980, and Shaked and Sutton 1982, 1983). In these models, location and market coverage (variables that are absent in the literature) play a paramount role in the determination of welfare losses. And Lerner's degree of monopoly (and thus, Harberger triangle) does not play any role determining welfare losses. Let us see why.

Section 2 considers the Hotelling model. Like Harberger (1954), we consider the percentage of welfare losses $(P W L)$ defined as the percentage at which equilibrium welfare falls short of the optimum. We first study how $P W L$ depends on the basic parameters that define the market such as the reservation price, transportation cost and marginal costs. We find that $P W L$ depends on these magnitudes in a non-monotonic way. The reason is that a change in these magnitudes not only changes welfare for given locations but also causes firms to reallocate. Next, we study if $P W L$ can be recovered from observable variables such as prices, marginal costs, location and the percentage of market coverage. We find that, in most cases, $P W L$ can be calculated from location and market coverage alone. $P W L$ decreases with market coverage (unless in the optimum the whole market should not be covered, in which case $P W L$ is constant) and with the distance from the market edges as it goes to the optimal location. Prices, marginal costs

\footnotetext{
${ }^{1}$ See Cowling and Mueller (1978, p. 728) for a summary of the criticism of Harberger's approach.
} 
(and thus markups) and demand elasticities do not help to find $P W L .^{2}$ Finally, $P W L$ might be large despite price competition. This shows that misallocation arising from the wrong location and lack of market cover could be very significant. ${ }^{3}$

Section 3 considers a model of a circular city (Salop 1979). Here $P W L$ depends on the magnitudes mentioned in the Hotelling case and also on the number of firms and the form of the transportation cost, which in Hotelling was quadratic and here is either linear or quadratic. As in the Hotelling model, $P W L$ decreases with the market coverage, unless in the optimum the whole market should not be covered, in which case $P W L$ is constant. Here, $P W L$ can be calculated in all cases. In other words, the indeterminacy that occurred in the Hotelling model does not arise here. As in the Hotelling model and for the same reason, $P W L$ is independent of demand elasticities and markups. Also, since here there are no misallocations due to firms being in the wrong locations, $P W L$ tends to be smaller than in the Hotelling model. But these losses may be large, up to $25 \%$. Finally, $P W L$ is not monotonic in the transportation cost for given market coverage. The reason is that a change in this magnitude changes welfare both in equilibrium and in the optimal allocations.

In Section 4 we study vertical (quality) differentiation (Gabszewicz and Thisse 1979, 1980 and Shaked and Sutton 1982, 1983). We assume that the parameter that measures the taste for quality is uniformly distributed across the population of consumers, assumed to be in a closed interval. Here we have two kinds of equilibria: those in which the whole market is covered and those in which not all the market is covered. ${ }^{4}$ We find that $P W L$ is a discontinuous function of the length of the interval mentioned above with a maximum of about $8.33 \%$. The discontinuity is caused by the fact that there is a point in which a low-quality firm freezes the quality of its good and does not serve consumers with very low taste for quality. This discontinuity arises at the point at

\footnotetext{
${ }^{2}$ For the role of markups and demand elasticities in models with exogenous location and quality choice see Corchón and Zudenkova (2009) .

${ }^{3}$ It can be argued that lack of market coverage cannot occur once entry is allowed in the model. The difficulty is that the Hotelling model becomes intractable with more than two firms so that, at this stage, it is difficult to gauge the importance of this criticism.

${ }^{4}$ We remark that, given a vector of parameters defining a market, equilibrium is unique. Thus, we cannot have the two classes of equilibria mentioned above simultaneously in the same market.
} 
which the market becomes uncovered. Welfare losses can be computed from relative prices and the degree of market coverage. ${ }^{5}$ When the whole market is covered, $P W L$ is single-peaked in relative prices reaching a maximum at an interior point. Thus an increase in relative prices can decrease or increase relative welfare losses. When not all the market is covered, $P W L$ depends only on market coverage, in a decreasing way, as expected.

Finally, Section 5 sums up our findings.

To the best of our knowledge, there is only one paper dealing with the issues tackled in this paper, namely Fan (2010). She studies mergers in the U.S. Daily Newspaper Market considering fixed location. She finds that ignoring adjustments in quality causes substantial differences in estimated effects of mergers. Apart from our common emphasis on variables other than prices and quantities, our studies are different. She focuses on welfare effects of mergers and we focus on the difference between optimal and equilibrium welfare. She focuses on quality and considers location fixed. Moreover, she does not consider the welfare impact of market coverage.

Summing up, our paper provides a theoretical study of welfare losses produced by oligopoly when location or quality is endogenous. Our study suggests that variables that have been overlooked in most empirical studies and the regulation literature might play a very important role. A shortcoming of our study is that it relies on assumptions that are unlikely to be met in actual markets like duopoly and symmetry. But if these assumptions are removed, computations are extremely complex and the models become unworkable. Thus, our paper is better understood as a pointer on the role of certain variables rather than a ready-to-use guide on the role of these variables in actual markets.

\section{Horizontal Differentiation: The Hotelling Model}

There are two firms producing a differentiated good. Consumers purchase either one unit or none of the differentiated good according to preferences, prices and the distribution of the two brands in product space. Brands are located in the interval $[0,1]$. Each consumer has a most-preferred brand specification $\tau$. Consumers are uniformly distributed along

\footnotetext{
${ }^{5}$ As in the Hotelling model, we do not consider entry in the vertical differentiation model.
} 
$[0,1]$ with density 1 . A brand located at point $x_{i}, i=1,2$, is valued for the consumer at point $\tau$ according to $U\left(x_{i}, \tau\right)=\alpha-\beta d^{\gamma}$ where $\alpha$ stands for the reservation price, $d=\left|x_{i}-\tau\right|$ is the Euclidean distance between $x_{i}$ and $\tau, \beta$ and $\gamma$ measure the importance of transportation costs, and $\alpha$ and $\beta$ are positive. The decision rule of consumer $\tau$ is: purchase one unit of brand $x_{i}$ if $\max _{i}\left[U\left(x_{i}, \tau\right)-p_{i}\right] \geq 0$, where $p_{i}$ is the price of brand $x_{i}, i=1,2$. The marginal cost of production is $c<\alpha$.

The model where $\gamma=1$ is not easily tractable since profit functions are discontinuous and nonconcave. ${ }^{6}$ To overcome these difficulties we assume that $\gamma=2$. Summing up:

Definition 1. A Linear Horizontal Market is a list of positive real numbers $\{\alpha, \beta, c\}$ with $\alpha>c .^{7}$

Let us consider a two-stage game. In the first stage, firms choose their locations $x_{1}$ and $x_{2}$ simultaneously. In the second stage, they choose prices simultaneously. Without loss of generality, assume that $x_{2} \geq x_{1}$. Firm $i$ 's profit is $\pi_{i}=\left(p_{i}-c\right) D_{i}$ where $D_{i}$ is the demand of firm $i$. It is easy to show that profit functions are continuous and concave and a Subgame Perfect Nash Equilibrium exists. ${ }^{8}$

We consider three symmetric equilibrium configurations: local monopolistic equilibrium, kinked equilibrium and competitive equilibrium. ${ }^{9}$ We characterize equilibria where consumers at the edges of the market buy the differentiated good. ${ }^{10}$

\footnotetext{
${ }^{6}$ For further details see d'Aspremont, Gabszewicz and Thisse (1979) and Economides (1984).

7 "Linear" relates to the linear form of the product space. "Horizontal" refers to the form of product differentiation. In Section 4 we will speak of a "Linear Vertical" market in which product differentiation is vertical.

${ }^{8}$ See Economides (1986) for the general case of $\gamma \leq 2$. Economides (1986) showed existence of a Subgame Perfect Nash Equilibrium for $\gamma \in(1.26,2]$.

${ }^{9}$ Salop (1979) used the term "kinked" for an equilibrium where the markets just touch and there is no tangency of demand. Economides (1984) used the term "touching" for such an equilibrium.

${ }^{10}$ Economides (1984) studied the case of a "not-too-high" reservation price where consumers at the edges of the market prefer not to purchase the differentiated good. He showed that under linear transportation cost function the equilibrium of the locations game is a local monopolistic one. The reason is that in the "competitive region" firms have incentives to relocate marginally away from each other and reach the "kinked" region. While in the "kinked" region firms still want to relocate away from each other and reach the "local monopolistic" region.
} 
Local monopolistic equilibrium. At this equilibrium, some consumers lying between two firms do not purchase the differentiated good, so the market is not fully covered. Each firm charges monopoly price $p_{m}$. A consumer with preferred brand $\tau \in\left(x_{1}, \frac{1}{2}\right)$ is indifferent between purchasing from firm 1 and not purchasing the differentiated good if $\alpha-\beta\left(\tau-x_{1}\right)^{2}-p_{m}=0$. Thus, firm 1's demand is $D_{1}\left(p_{m}\right)=\tau=x_{1}+\sqrt{\frac{\alpha-p_{m}}{\beta}}$. In the second stage firm 1's profit maximization with respect to $p_{m}$ yields

$$
p_{m}\left(x_{1}\right)=\frac{1}{9}\left(6 \alpha+3 c-2 \beta x_{1}^{2}+2 \sqrt{\beta x_{1}^{2}\left(3(\alpha-c)+\beta x_{1}^{2}\right)}\right) .
$$

Plugging $p_{m}\left(x_{1}\right)$ into firm 1's profit yields

$$
\pi_{1}\left(x_{1}\right)=\left(p_{m}\left(x_{1}\right)-c\right)\left(x_{1}+\sqrt{\frac{\alpha-p_{m}\left(x_{1}\right)}{\beta}}\right) .
$$

After tedious calculations one finds that $\frac{\partial \pi_{1}}{\partial x_{1}}>0$, so firms have incentives to relocate towards the market center still maintaining local monopoly power. Firms will move to the market center until consumers at the edges of the market are just indifferent between buying the differentiated good and not. One can check that in this case the firms' marginal relocation tendency becomes zero.

Consumers at the edges of the market are indifferent between buying the good and not buying it, which amounts to $x_{1}-\sqrt{\frac{\alpha-p_{m}\left(x_{1}\right)}{\beta}}=0$. Consumers at the market center do not buy the differentiated good, which amounts to $x_{1}+\sqrt{\frac{\alpha-p_{m}\left(x_{1}\right)}{\beta}}<\frac{1}{2}$. These two conditions yield a local monopolistic equilibrium: firm 1 chooses $x_{1}^{*}=\sqrt{\frac{\alpha-c}{5 \beta}}$, and by symmetry firm 2 chooses $x_{2}^{*}=1-\sqrt{\frac{\alpha-c}{5 \beta}}$. Both firms charge the same price $p_{m}^{*}=\frac{4 \alpha+c}{5}$. This equilibrium exists for $\frac{\alpha-c}{\beta}<\frac{5}{16}$.

Definition 2. A Local Monopolistic Equilibrium for a linear horizontal market $\{\alpha, \beta, c\}$ with $\frac{\alpha-c}{\beta}<\frac{5}{16}$ is a price $p_{m}^{*}=\frac{4 \alpha+c}{5}$ and brand locations $\left\{x_{m 1}^{*}, x_{m 2}^{*}\right\}=\left\{\sqrt{\frac{\alpha-c}{5 \beta}}, 1-\sqrt{\frac{\alpha-c}{5 \beta}}\right\}$.

Kinked equilibrium. At a kinked equilibrium, markets just "touch". A consumer with preferred brand specification $\tau=\frac{1}{2}$ is indifferent between purchasing from firm 1 or from firm 2 at price $p_{k}$ and not purchasing the differentiated good if $\alpha-\beta\left(\frac{1}{2}-x_{1}\right)^{2}-p_{k}=0$. 
Thus, $p_{k}\left(x_{1}\right)=\alpha-\beta\left(\frac{1}{2}-x_{1}\right)^{2}$. At the same time, firms still enjoy local monopolistic power, therefore $p_{k}\left(x_{1}\right)=p_{m}\left(x_{1}\right)$, which yields

$$
x_{1}^{*}=1-\frac{1}{2} \sqrt{4 \frac{\alpha-c}{\beta}+1} \text { and } p_{k}^{*}=\frac{1}{2}(2 c-\beta+\sqrt{\beta(4(\alpha-c)+\beta)}) .
$$

In the kinked equilibrium firms behave as local monopolists but maintain full market coverage so $x_{1}^{*}>0$ or $\frac{\alpha-c}{\beta}<\frac{3}{4}$. The consumers at the edges of the market purchase the differentiated good so $\alpha-\beta\left(x_{1}^{*}\right)^{2}-p_{k}^{*} \geq 0$, which simplifies to $\frac{\alpha-c}{\beta} \geq \frac{5}{16}$.

Note that for $\frac{3}{4} \leq \frac{\alpha-c}{\beta}<\frac{5}{4}$ there is a kinked equilibrium with $\left\{x_{1}^{*}, x_{2}^{*}\right\}=\{0,1\}$ and $p_{k}^{*}=\alpha-\frac{\beta}{4}$, which is an intermediate case between the kinked equilibrium described above and the competitive equilibrium, which is analyzed below.

Definition 3. A Kinked Equilibrium for a linear horizontal market $\{\alpha, \beta, c\}$ with $\frac{5}{16} \leq$ $\frac{\alpha-c}{\beta}<\frac{3}{4}$ is a price $p_{k}^{*}=\frac{1}{2}(2 c-\beta+\sqrt{\beta(4(\alpha-c)+\beta)})$ and brand locations $\left\{x_{k 1}^{*}, x_{k 2}^{*}\right\}=$ $\left\{1-\frac{1}{2} \sqrt{4 \frac{\alpha-c}{\beta}+1}, \frac{1}{2} \sqrt{4 \frac{\alpha-c}{\beta}+1}\right\}$.

A Kinked Equilibrium for a linear horizontal market $\{\alpha, \beta, c\}$ with $\frac{3}{4} \leq \frac{\alpha-c}{\beta}<\frac{5}{4}$ is a price $p_{k}^{*}=\alpha-\frac{\beta}{4}$ and brand locations $\left\{x_{k 1}^{*}, x_{k 2}^{*}\right\}=\{0,1\}$.

Competitive equilibrium. A consumer with preferred brand specification $\tau \in\left(x_{1}, x_{2}\right)$, is indifferent between purchasing brand $x_{1}$ and purchasing brand $x_{2}$ if

$$
\alpha-\beta\left(\tau-x_{1}\right)^{2}-p_{1}=\alpha-\beta\left(x_{2}-\tau\right)^{2}-p_{2} \Rightarrow \tau=\frac{p_{2}-p_{1}}{2 \beta\left(x_{2}-x_{1}\right)}+\frac{x_{1}+x_{2}}{2},
$$

so the demands $D_{1}\left(p_{1}, p_{2}\right)$ and $D_{2}\left(p_{1}, p_{2}\right)$ faced by firms 1 and 2 read

$$
\begin{aligned}
& D_{1}\left(p_{1}, p_{2}\right) \equiv \tau=\frac{p_{2}-p_{1}}{2 \beta\left(x_{2}-x_{1}\right)}+\frac{x_{1}+x_{2}}{2} \\
& D_{2}\left(p_{1}, p_{2}\right) \equiv 1-\tau=1-\frac{p_{2}-p_{1}}{2 \beta\left(x_{2}-x_{1}\right)}-\frac{x_{1}+x_{2}}{2}
\end{aligned}
$$

Firm $i$ 's profit maximization with respect to $p_{i}$ yields

$$
p_{1}=c+\frac{\beta}{3}\left(x_{2}-x_{1}\right)\left(2+x_{1}+x_{2}\right) \text { and } p_{2}=c+\frac{\beta}{3}\left(x_{2}-x_{1}\right)\left(4-x_{1}-x_{2}\right),
$$

and corresponding profits become

$$
\pi_{1}=\frac{\beta}{18}\left(x_{2}-x_{1}\right)\left(2+x_{1}+x_{2}\right)^{2} \text { and } \pi_{2}=\frac{\beta}{18}\left(x_{2}-x_{1}\right)\left(4-x_{1}-x_{2}\right)^{2} .
$$


The "marginal relocation tendency of firms" reads $\frac{\partial \pi_{1}}{\partial x_{1}}<0$ and $\frac{\partial \pi_{2}}{\partial x_{2}}>0$. Thus, the firms have incentives to relocate marginally away from each other. The equilibrium has two firms locating at the two extremes of the product space (maximal differentiation) $x_{1}^{*}=0$ and $x_{2}^{*}=1$ and charging the same price $p_{c}^{*}=c+\beta$. At the competitive equilibrium the entire market is covered, so $\alpha-\beta\left(\frac{1}{2}\right)^{2}-p_{c}^{*} \geq 0$, which amounts to $\frac{\alpha-c}{\beta} \geq \frac{5}{4}$.

Definition 4. A Competitive Equilibrium for a linear horizontal market $\{\alpha, \beta, c\}$ with $\frac{\alpha-c}{\beta} \geq \frac{5}{4}$ is a price $p_{c}^{*}=c+\beta$ and a list of brand locations $\left\{x_{c 1}^{*}, x_{c 2}^{*}\right\}=\{0,1\}$.

Thus, the equilibrium configuration depends on the values taken by $\frac{\alpha-c}{\beta}$.

- For low values of $\frac{\alpha-c}{\beta}$ (i.e. $\frac{\alpha-c}{\beta}<\frac{5}{16}$ ), there exists a local monopolistic symmetric equilibrium where the firms enjoy monopolistic power at the market edges while consumers in the center of the market do not purchase the differentiated commodity. The higher the value of $\frac{\alpha-c}{\beta}$, the closer firm 1 (resp. firm 2) to location $\frac{1}{4}$ (resp. $\frac{3}{4}$ ).

- If $\frac{\alpha-c}{\beta}=\frac{5}{16}$ there exists a kinked equilibrium where the whole market is covered and $\left\{x_{k 1}^{*}, x_{k 2}^{*}\right\}=\left\{\frac{1}{4}, \frac{3}{4}\right\}$. In this equilibrium firms enjoy all the monopolistic power: they sell to consumers both at the market edges and in the market center, and still do not become involved in competition with one another.

- If $\frac{5}{16}<\frac{\alpha-c}{\beta}<\frac{3}{4}$ there is a kinked equilibrium where the whole market is covered, firms do not compete for the market center consumers (the markets just touch) but do not extract all the possible surplus from the market edges consumers: the consumers at the edges of the market get positive surplus by purchasing the differentiated commodity.

- If $\frac{3}{4} \leq \frac{\alpha-c}{\beta}<\frac{5}{4}$ there exists a kinked equilibrium where the whole market is covered, firms are situated at the edges of the market $\left\{x_{k 1}^{*}, x_{k 2}^{*}\right\}=\{0,1\}$ and do not compete for the market center consumer (the markets just touch).

- Finally, for high values of $\frac{\alpha-c}{\beta}$ (i.e. $\frac{\alpha-c}{\beta} \geq \frac{5}{4}$ ) there is a competitive equilibrium where the entire market is covered, the firms are situated at the edges of the market $\left\{x_{c 1}^{*}, x_{c 2}^{*}\right\}=\{0,1\}$ and compete for the market center consumers.

Define social welfare $W$ as the gross consumers' surplus minus costs (i.e., the mar- 
ginal cost and the consumers' transportation costs):

$$
W=2 \int_{0}^{\tau}\left(\alpha-c-\beta\left(t-x_{1}^{*}\right)^{2}\right) d t
$$

which is equal in equilibrium to

$$
W^{*}=\left\{\begin{array}{lll}
\frac{56}{15 \sqrt{5}}(\alpha-c) \sqrt{\frac{\alpha-c}{\beta}} & \text { if } & \frac{\alpha-c}{\beta}<\frac{5}{16} \\
\frac{3}{4} \beta \sqrt{4 \frac{\alpha-c}{\beta}+1}-\frac{5}{6} \beta & \text { if } & \frac{5}{16} \leq \frac{\alpha-c}{\beta}<\frac{3}{4} \\
\alpha-c-\frac{\beta}{12} & \text { if } & \frac{\alpha-c}{\beta} \geq \frac{3}{4}
\end{array}\right.
$$

Note that the social welfare does not depend on the equilibrium price, which is just a transfer from the consumers to the producers. In our framework the social welfare is only affected by the market coverage and firms' locations, which determine the consumers' transportation costs and the consumers' surplus net of marginal cost. This is the reason why the social welfare in a kinked equilibrium for $\frac{3}{4} \leq \frac{\alpha-c}{\beta}<\frac{5}{4}$ is the same as the social welfare in a competitive equilibrium for $\frac{\alpha-c}{\beta} \geq \frac{5}{4}$. Indeed, in both cases the whole market is covered and the firms are located at the market edges.

A social planner would choose the price equal to marginal cost and the firms' locations to maximize the social welfare. One can check that the social welfare in the optimum, denoted by $W^{o}$, is equal to

$$
W^{o}=\left\{\begin{array}{lll}
\frac{8}{3}(\alpha-c) \sqrt{\frac{\alpha-c}{\beta}} & \text { if } & \frac{\alpha-c}{\beta}<\frac{1}{16} \\
\alpha-c-\frac{\beta}{48} & \text { if } & \frac{\alpha-c}{\beta} \geq \frac{1}{16}
\end{array}\right.
$$

where the first line corresponds to the case where not all the market is covered and consumers at the market center do not purchase the differentiated commodity; the second line corresponds to the case where the entire market is covered and the firms are located at $\left\{x_{1}^{o}, x_{2}^{o}\right\}=\left\{\frac{1}{4}, \frac{3}{4}\right\}$.

The percentage of welfare losses is defined as

$$
P W L \equiv 1-\frac{W^{*}}{W^{o}}
$$




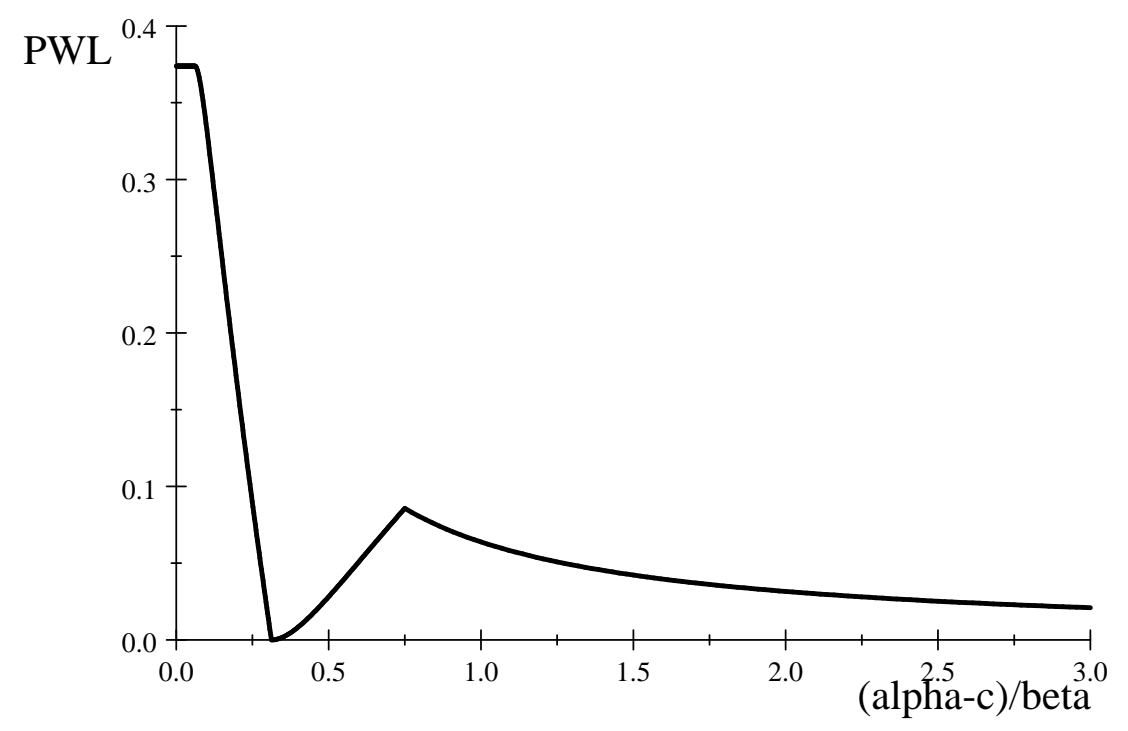

Figure 2.1: $P W L$ as a function of $\frac{\alpha-c}{\beta}$.

and is equal to

$$
P W L=\left\{\begin{array}{lll}
1-\frac{7}{5 \sqrt{5}} \approx 0.3739 & \text { if } & \frac{\alpha-c}{\beta}<\frac{1}{16} \\
1-\frac{\frac{56}{15 \sqrt{5}} \sqrt{\frac{\alpha-c}{\beta}}}{1-\frac{1}{48} \frac{\beta}{\alpha-c}} & \text { if } & \frac{1}{16} \leq \frac{\alpha-c}{\beta}<\frac{5}{16} \\
1-\frac{\frac{3}{4} \sqrt{4 \frac{\alpha-c}{\beta}+1}-\frac{5}{6}}{\frac{\alpha-c}{\beta}-\frac{1}{48}} & \text { if } & \frac{5}{16} \leq \frac{\alpha-c}{\beta}<\frac{3}{4} \\
1-\frac{\frac{\alpha-c}{\beta}-\frac{1}{12}}{\frac{\alpha-c}{\beta}-\frac{1}{48}} & \text { if } & \frac{\alpha-c}{\beta} \geq \frac{3}{4}
\end{array}\right.
$$

Figure 2.1 depicts $P W L$ as a function of $\frac{\alpha-c}{\beta}$. Note that $P W L$ is not monotonic in $\frac{\alpha-c}{\beta}$. The reason is that a change in $\frac{\alpha-c}{\beta}$ not only changes welfare for given locations but it causes reallocation effects that may overcome the latter effect. For instance, a decrease in transportation costs $\beta$ makes the economy more competitive, but at the same time causes firms to relocate away from each other, increasing monopoly power.

- For $\frac{\alpha-c}{\beta}<\frac{1}{16} P W L$ is constant. In this case the market is not covered either in equilibrium or in the optimum. Welfare losses are due to the firms' monopolistic behavior. 
- For $\frac{1}{16} \leq \frac{\alpha-c}{\beta}<\frac{5}{16}, P W L$ is decreasing in $\frac{\alpha-c}{\beta}$. In this case in equilibrium the market is not covered, while in the optimum it should be covered. Indeed, with an increase of $\frac{\alpha-c}{\beta}$ the equilibrium configuration gets closer to the optimum configuration $\left\{x_{1}^{o}, x_{2}^{o}\right\}=\left\{\frac{1}{4}, \frac{3}{4}\right\}$.

- For $\frac{\alpha-c}{\beta}=\frac{5}{16} P W L=0$ since equilibrium configuration is the same as the optimum one: the whole market is covered and the firms are located at $\left\{\frac{1}{4}, \frac{3}{4}\right\}$.

- When $\frac{5}{16}<\frac{\alpha-c}{\beta}<\frac{3}{4} P W L$ is increasing in $\frac{\alpha-c}{\beta}$. In this case the higher $\frac{\alpha-c}{\beta}$ is, the closer the firms locate to the edges of the market (so the higher the consumers' transportation costs are). This effect exacerbates welfare losses.

- Finally, when $\frac{\alpha-c}{\beta} \geq \frac{3}{4} P W L$ is decreasing in $\frac{\alpha-c}{\beta}$. Here in equilibrium, the firms locate at the market edges and compete for the consumers located at the market center. Thus, $P W L$ is decreasing in $\frac{\alpha-c}{\beta}$.

So far we have analyzed the relationship between $P W L$ and the parameters defining a linear horizontal market $\{\alpha, \beta, c\}$. Let us now relate $P W L$ with observable variables. An Observation is a tuple $\{\mathfrak{p}, \mathfrak{c}, \mathfrak{x}, \mathfrak{m}\}$ of market price $\mathfrak{p}$, marginal cost $\mathfrak{c}(\mathfrak{p}>\mathfrak{c})$, the relative distance from the market edges to brand locations $\mathfrak{x} \in\left[0, \frac{1}{4}\right]$ and the percentage of market coverage $\mathfrak{m} \in[0,1]$. We assume that the marginal cost is observable because under constant returns, the marginal cost equals the average variable cost, which in principle can be observed (wages, raw materials, etc.). Then, we have the following:

Proposition 1. Given an observation $\{\mathfrak{p}, \mathfrak{c}, \mathfrak{x}, \mathfrak{m}\}$ there is a linear horizontal market $\{\alpha, \beta, \mathfrak{c}\}$ such that $\{\mathfrak{p}, \mathfrak{x}, 1-\mathfrak{x}\}$ is

i) a local monopolistic equilibrium for this market when $\mathfrak{m}<1$ and $0 \leq \mathfrak{x}<\frac{1}{4}$;

ii) a kinked equilibrium for this market when $\mathfrak{m}=1$ and $0<\mathfrak{x} \leq \frac{1}{4}$;

iii) either a kinked equilibrium or a competitive equilibrium for this market when $\mathfrak{m}=1$ and $\mathfrak{x}=0$;

$P W L$ in each case is given by

$$
P W L=\left\{\begin{array}{lll}
1-\frac{7}{5 \sqrt{5}} \approx 0.3739 & \text { if } & \mathfrak{m}<1,0 \leq \mathfrak{x}<\frac{1}{4 \sqrt{5}} \\
1-\frac{89 \mathfrak{x}^{3}}{240 \mathfrak{x}^{2}-1} & \text { if } \quad \mathfrak{m}<1, \frac{1}{4 \sqrt{5}} \leq \mathfrak{x}<\frac{1}{4} \\
1-\frac{32-72 \mathfrak{x}}{35-48 \mathfrak{x}(2-\mathfrak{x})} & \text { if } \quad \mathfrak{m}=1,0<\mathfrak{x} \leq \frac{1}{4} \\
\in\left(0, \frac{3}{35}\right], \frac{3}{35} \approx 0.0857 & \text { if } \quad \mathfrak{m}=1, \mathfrak{x}=0
\end{array}\right.
$$


Proof: First, consider the case where not all the market is covered, i.e. $\mathfrak{m}<1$ and $\mathfrak{x}<\frac{1}{4}$. Let $\alpha=\frac{5 \mathfrak{p}-\mathfrak{c}}{4}$ and $\beta=\frac{\mathfrak{p}-\mathfrak{c}}{4 \mathfrak{r}^{2}}$. We easily see that the linear horizontal market $\{\alpha, \beta, \mathfrak{c}\}$ yields a local monopolistic equilibrium where $p_{m}^{*}=\mathfrak{p}$ and $\left\{x_{m 1}^{*}, x_{m 2}^{*}\right\}=$ $\{\mathfrak{x}, 1-\mathfrak{x}\}$. When $\mathfrak{x}<\frac{1}{4 \sqrt{5}}$ in the optimum not all the market is covered and $P W L=$ $1-\frac{7}{5 \sqrt{5}}$. When $\mathfrak{x} \geq \frac{1}{4 \sqrt{5}}$ in the optimum the entire market should be covered. Plugging $\alpha=\frac{5 \mathfrak{p}-\mathfrak{c}}{4}$ and $\beta=\frac{\mathfrak{p}-\mathfrak{c}}{4 \mathfrak{r}^{2}}$ into the second line of (2.1) yields the second line of (2.2) for $P W L$ as a function of observables.

Next, consider the case where the entire market is covered, i.e. $\mathfrak{m}=1$, and the firms do not locate at the edges of the market, i.e. $0<\mathfrak{x} \leq \frac{1}{4}$. Let $\alpha=\frac{1}{2}(3 \mathfrak{p}-\mathfrak{c}-2 \mathfrak{x}(\mathfrak{p}-\mathfrak{c}))$ and $\beta=\frac{2(\mathfrak{p}-\mathfrak{c})}{1-2 \mathfrak{x}}$. It is straightforward to check that the linear horizontal market $\{\alpha, \beta, \mathfrak{c}\}$ yields a kinked equilibrium where $p_{k}^{*}=\mathfrak{p}$ and $\left\{x_{k 1}^{*}, x_{k 2}^{*}\right\}=\{\mathfrak{x}, 1-\mathfrak{x}\}$. Plugging $\alpha=$ $\frac{1}{2}(3 \mathfrak{p}-\mathfrak{c}-2 \mathfrak{x}(\mathfrak{p}-\mathfrak{c}))$ and $\beta=\frac{2(\mathfrak{p}-\mathfrak{c})}{1-2 \mathfrak{x}}$ into the third line of $(2.1)$ yields the third line of (2.2) for $P W L$ as a function of observables.

Finally, let us consider the case where the entire market is covered, i.e. $\mathfrak{m}=1$, and the firms locate at the edges of the market, i.e. $\mathfrak{x}=0$. Here, with available observables there is no way to distinguish between the kinked equilibrium where the firms are located at the market edges and the competitive equilibrium.

In the case of the kinked equilibrium where the firms are located at the market edges, let us fix $\frac{5 \mathfrak{p}-\mathfrak{c}}{4}<\alpha \leq \frac{3 \mathfrak{p}-\mathfrak{c}}{2}$ (for condition $\frac{3}{4} \leq \frac{\alpha-\mathfrak{c}}{\beta}<\frac{5}{4}$ to hold) and let $\beta=4(\alpha-\mathfrak{p})$. It is straightforward to check that the linear horizontal market $\{\alpha, \beta, \mathfrak{c}\}$ yields a kinked equilibrium where $p_{k}^{*}=\mathfrak{p}$ and $\left\{x_{k 1}^{*}, x_{k 2}^{*}\right\}=\{0,1\}$. From the fourth line of $(2.1)$ we get PWL in the kinked equilibrium, denoted as $P W L_{k}$, as a function of observables and $\alpha$ :

$$
P W L_{k}=\frac{3(\alpha-\mathfrak{p})}{11 \alpha+\mathfrak{p}-12 \mathfrak{c}} \text { where } \frac{5 \mathfrak{p}-\mathfrak{c}}{4}<\alpha \leq \frac{3 \mathfrak{p}-\mathfrak{c}}{2}
$$

which is increasing in $\alpha$ and achieves its maximal value of $\frac{3}{35}$ at $\alpha=\frac{3 \mathfrak{p}-\mathfrak{c}}{2}$ and its minimal value of $\frac{3}{59}$ at $\alpha=\frac{5 \mathfrak{p}-\mathfrak{c}}{4}$. This and the continuity of $P W L_{k}$ with respect to $\alpha$ imply that $P W L_{k} \in\left(\frac{3}{59}, \frac{3}{35}\right]$.

In the case of the competitive equilibrium, let us fix $\alpha \geq \frac{5 \mathfrak{p}-\mathfrak{c}}{4}$ (for condition $\frac{\alpha-c}{\beta} \geq \frac{5}{4}$ to hold) and let $\beta=\mathfrak{p}-\mathfrak{c}$. It is easy to show that the linear horizontal market $\{\alpha, \beta, \mathfrak{c}\}$ yields a competitive equilibrium where $p_{c}^{*}=\mathfrak{p}$ and $\left\{x_{c 1}^{*}, x_{c 2}^{*}\right\}=\{0,1\}$. From the fourth line of (2.1) we get $P W L$ in the competitive equilibrium, denoted as $P W L_{c}$, as a function 


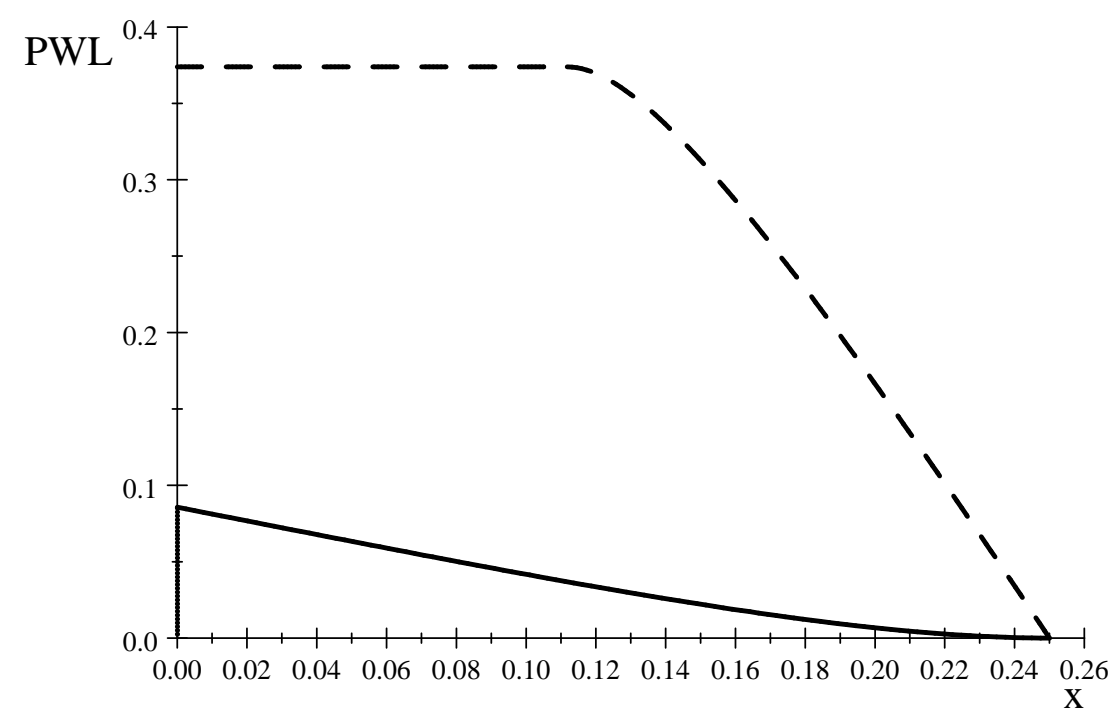

Figure 2.2: $P W L$ as a function of observable relative distance $\mathfrak{x}$ from the market edges to brand locations when the market is not covered, $\mathfrak{m}<1$ (dash), and when the market is covered, $\mathfrak{m}=1$ (solid).

of observables and $\alpha$ :

$$
P W L_{c}=\frac{3(\mathfrak{p}-\mathfrak{c})}{48 \alpha-47 \mathfrak{c}-\mathfrak{p}} \text { where } \alpha \geq \frac{5 \mathfrak{p}-\mathfrak{c}}{4}
$$

which is decreasing in $\alpha$ and achieves its maximal value of $\frac{3}{59}$ at $\alpha=\frac{5 \mathfrak{p}-\mathfrak{c}}{4}$ and goes to 0 as $\alpha$ goes to infinity. This and the continuity of $P W L_{c}$ with respect to $\alpha$ imply that $P W L_{c} \in\left(0, \frac{3}{59}\right]$. Thus, in the case where the entire market is covered and the firms locate at the edges of the market, i.e. $\mathfrak{m}=1$ and $\mathfrak{x}=0, P W L \in\left(0, \frac{3}{35}\right]$ with $\frac{3}{35} \approx 0.0857$.

Figure 2.2 depicts $P W L$ as a function of observables. In general, as expected, $P W L$ decreases with market coverage (unless in the optimum the whole market should not be covered, in which case $P W L$ is constant) and with the distance $\mathfrak{x}$ from the market edges as it goes to the optimal location $\frac{1}{4}$. Other points are worth discussion. 
Firstly, $P W L$ can be calculated from location and market coverage in three out of four cases in (2.2). Only in the case where the whole market is covered and the firms locate at the market edges, i.e. $\mathfrak{m}=1$ and $\mathfrak{x}=0$, could $P W L$ be any number between zero and $\frac{3}{35}$, even if price and marginal cost are observed. ${ }^{11}$ Knowledge of demand elasticity, denoted by $\varepsilon$, cannot be used to break the indeterminacy of $P W L$. In the case of a kinked equilibrium, the demand function is not differentiable so demand elasticity is not well defined. In the case of a competitive equilibrium, from the first order condition of profit maximization $\varepsilon=\frac{\mathfrak{p}}{\mathfrak{p}-\mathfrak{c}}$, so knowledge of $\varepsilon$ is redundant. The same argument applies if the cross elasticity of demand $\frac{\partial D_{i}}{\partial p_{j}} \frac{p_{j}}{D_{i}}$, denoted by $\rho$, is observable since in our model, in equilibrium, $\rho=\varepsilon .^{12}$

Secondly, $P W L$ is independent of demand elasticities (own and cross) and markups. This is explained by the fact that as demand is totally inelastic, a high price, unless it induces not buying the good, does not cause welfare losses. As we remarked before, an increase in price just redistributes the surplus between consumers and firms. This makes a difference with models in which consumers may buy several goods where demand elasticities and markups can be used to find $P W L$ even though their impact is sometimes counterintuitive. See Corchón and Zudenkova (2009).

Thirdly, $P W L$ might be large, larger than in the Cournot model with linear demand and cost functions, which in the duopoly case is around 11\% (Anderson and Renault 2003). And this occurs despite price competition in the Hotelling model. This shows that misallocation arising from the wrong location could be very significant, especially when not all the market is covered. See Figure 2.2.

\footnotetext{
${ }^{11} P W L$ could be calculated if the reservation price is observed. The latter is usually thought to be private information but, in some cases, it can be elicited by the mechanism of Becker, DeGroot and Marschak (1964). For the limitations of this mechanism see Horowitz (2006) and the references there.

${ }^{12}$ However, if it could be determined whether the demand function is differentiable, we would know if the market is in a kinked equilibrium-where $P W L$ lies between $\frac{3}{59}$ and $\frac{3}{35}-$ or in a competitive equilibrium where $P W L$ lies between 0 and $\frac{3}{59}$.
} 


\section{Horizontal Differentiation: The Salop Model}

Consider the economy described in the previous section with the following changes. Firstly, the product space of the monopolistically competitive industry is a circle with a perimeter equal to 1 . Secondly, there are $n$ brands of the differentiated good available at prices $p_{1}, \ldots, p_{n}$. As before, each firm is allowed to produce just one brand. Thirdly, firms do not choose their brand location, but are automatically located equidistant from one another on the circle. ${ }^{13}$ This simplification allows this model to be solved for linear $(\gamma=1)$ and quadratic $(\gamma=2)$ transportation costs. Summing up:

Definition 5. A Circular Market is a list $\{\alpha, \beta, c, n, \gamma\}$, where $\alpha, \beta, c \in \mathbb{R}^{+}, \gamma \in\{1,2\}$, $n \in \mathbb{N}$, and $\alpha>c$.

Firm $i$ 's profit is $\pi_{i}=\left(p_{i}-c\right) D_{i}$ where $D_{i}$ is the demand firm $i$ faces and $p_{i}$ is the price chosen by firm $i$. As before, we consider three symmetric equilibrium configurations: local monopolistic equilibrium, kinked equilibrium and competitive equilibrium.

Local monopolistic equilibrium. At the local monopolistic equilibrium, some consumers lying between two neighboring firms do not purchase the differentiated commodity, so the market is not covered. Each firm charges monopoly price $p_{m}$. A consumer with preferred brand specification located at the distance $\tau \in\left(0, \frac{1}{2 n}\right)$ from firm $i$ 's brand specification, is indifferent between purchasing from firm $i$ and not purchasing the differentiated commodity if $\alpha-\beta \tau^{\gamma}-p_{m}=0$. Thus, firm $i$ 's demand is

$$
D_{i}\left(p_{m}\right)=2 \tau=2\left(\frac{\alpha-p_{m}}{\beta}\right)^{\frac{1}{\gamma}} .
$$

Firm $i$ 's profit maximization yields $p_{m}=\frac{c+\gamma \alpha}{1+\gamma}$. In local monopolistic equilibrium not all the market is covered, which amounts to $\frac{(\alpha-c) n^{\gamma}}{\beta}<\frac{1+\gamma}{2^{\gamma}}$.

Definition 6. A Local Monopolistic Equilibrium for a circular market $\{\alpha, \beta, c, n, \gamma\}$ with $\frac{(\alpha-c) n^{\gamma}}{\beta}<\frac{1+\gamma}{2^{\gamma}}$ is a price $p_{m}^{*}=\frac{c+\gamma \alpha}{1+\gamma}$ and a quantity $D_{i}\left(p_{m}^{*}\right)=2\left(\frac{\alpha-c}{(1+\gamma) \beta}\right)^{\frac{1}{\gamma}}$, $i=1,2, \ldots, n$.

\footnotetext{
${ }^{13}$ See Economides (1989) where this assumption emerges in equilibrium in a model where firms decide on locations.
} 
Kinked equilibrium. At a kinked equilibrium, markets just "touch". A consumer with preferred brand specification located at the distance $\tau=\frac{1}{2 n}$ from a firm's brand specification, is indifferent between purchasing from a firm or from its closest neighbor at price $p_{k}$ and not purchasing the differentiated commodity if $\alpha-\beta\left(\frac{1}{2 n}\right)^{\gamma}-p_{k}=0$. Thus, $p_{k}=\alpha-\beta\left(\frac{1}{2 n}\right)^{\gamma}$. In kinked equilibrium the entire market is covered, $D_{i}=\frac{1}{n}$, but there is no tangency of demand. These conditions amount to $\frac{1+\gamma}{2^{\gamma}} \leq \frac{(\alpha-c) n^{\gamma}}{\beta} \leq \frac{1}{2^{\gamma}}+1$.

Definition 7. A Kinked Equilibrium for a circular market $\{\alpha, \beta, c, n, \gamma\}$ with $\frac{1+\gamma}{2 \gamma} \leq$ $\frac{(\alpha-c) n^{\gamma}}{\beta} \leq \frac{1}{2^{\gamma}}+1$ is a price $p_{k}^{*}=\alpha-\beta\left(\frac{1}{2 n}\right)^{\gamma}$ and a quantity $D_{i}\left(p_{k}^{*}\right)=\frac{1}{n}, i=1,2, \ldots, n$.

Competitive equilibrium. Firms are located equidistant from one another and compete in prices given these locations. Since they are located symmetrically, they will charge the same price $p_{c}$ in the equilibrium. Firm $i$ has two potential competitors, namely firms $i-1$ and $i+1$. Suppose that it chooses price $p_{i} \equiv p$. A consumer with preferred brand specification located at the distance $\tau \in\left(0, \frac{1}{n}\right)$ from firm $i$ 's brand specification, is indifferent between purchasing from firm $i$ and from $i$ 's closest neighbor if $\alpha-\beta \tau^{\gamma}-p=\alpha-\beta\left(\frac{1}{n}-\tau\right)^{\gamma}-p_{c}$. Thus, $i$ 's demand reads

$$
D_{i}\left(p, p_{c}\right)=2 \tau=\frac{1}{n}+\frac{p_{c}-p}{\beta} n^{\gamma-1} .
$$

Firm $i$ 's profit maximization yields (in equilibrium $p=p_{c}$ ) $p_{c}=c+\frac{\beta}{n^{\gamma}}$. In competitive equilibrium all consumers receive positive net surplus so the entire market is covered, which amounts to $\frac{(\alpha-c) n^{\gamma}}{\beta}>\frac{1}{2^{\gamma}}+1$.

Definition 8. A Competitive Equilibrium for a circular market $\{\alpha, \beta, c, n, \gamma\}$ with $\frac{(\alpha-c) n^{\gamma}}{\beta}>\frac{1}{2^{\gamma}}+1$ is a price $p_{c}^{*}=c+\frac{\beta}{n^{\gamma}}$ and a quantity $D_{i}\left(p_{c}^{*}, p_{c}^{*}\right)=\frac{1}{n}, i=1,2, \ldots, n$.

As before, the equilibrium configuration depends on the underlying parameters. When $\frac{\alpha-c}{\beta}$ and $n$ are small, the market is small (either because the reservation price and/or the number of firms are small or because marginal costs and/or transportation costs $\beta$ are large) and local monopolies arise. ${ }^{14}$ For intermediate values of $\frac{(\alpha-c) n^{\gamma}}{\beta}$

\footnotetext{
${ }^{14}$ Notice that $\gamma$ appears on both sides of the inequalities defining different equilibria and its effect on them is not straightforward.
} 
markets touch and a kinked equilibrium arises. Finally, when $\frac{(\alpha-c) n^{\gamma}}{\beta}$ is large enough the economy becomes competitive.

Social welfare, $W$, defined as before is

$$
W=2 n \int_{0}^{\tau}\left(\alpha-c-\beta t^{\gamma}\right) d t
$$

which in the equilibrium reads for $\gamma=1,2$

$$
W^{*}=\left\{\begin{array}{lll}
\frac{2 \gamma(2+\gamma)}{(1+\gamma)^{2+\frac{1}{\gamma}}} \frac{(\alpha-c)^{1+\frac{1}{\gamma}} n}{\beta^{\frac{1}{\gamma}}} & \text { if } & \frac{(\alpha-c) n^{\gamma}}{\beta}<\frac{1+\gamma}{2^{\gamma}} \\
\alpha-c-\frac{\beta}{2^{\gamma}(1+\gamma) n^{\gamma}} & \text { if } & \frac{(\alpha-c) n^{\gamma}}{\beta} \geq \frac{1+\gamma}{2^{\gamma}}
\end{array}\right.
$$

Notice that, again, the social welfare does not depend on the equilibrium price, which is just a transfer from the consumers to the producers. In our framework the social welfare is only affected by the market coverage, which determines the consumers' transportation costs and the consumers' surplus net of marginal cost.

A social planner would choose the price equal to marginal cost, which affects the market coverage and, therefore, the consumers' transportation costs and the consumers' surplus net of marginal cost. It is straightforward to show that the social welfare in the optimum, denoted by $W^{o}$, reads

$$
W^{o}=\left\{\begin{array}{lll}
\frac{2 \gamma}{1+\gamma} \frac{(\alpha-c)^{1+\frac{1}{\gamma}} n}{\beta^{\frac{1}{\gamma}}} & \text { if } & \frac{(\alpha-c) n^{\gamma}}{\beta}<\frac{1}{2^{\gamma}} \\
\alpha-c-\frac{\beta}{2^{\gamma}(1+\gamma) n^{\gamma}} & \text { if } & \frac{(\alpha-c) n^{\gamma}}{\beta} \geq \frac{1}{2^{\gamma}}
\end{array}\right.
$$

where the first (resp. second) line corresponds to the case where not all the market (resp. the whole market) is covered in the optimum and $\gamma=1,2$. The percentage of welfare losses, defined as before, equals

$$
P W L=\left\{\begin{array}{lll}
1-\frac{2+\gamma}{(1+\gamma)^{1+\frac{1}{\gamma}}} & \text { if } & \frac{(\alpha-c) n^{\gamma}}{\beta}<\frac{1}{2^{\gamma}} \\
1-\frac{2 \gamma(2+\gamma)}{2+\frac{1}{\gamma}}\left(\frac{(\alpha-c) n^{\gamma}}{\beta}\right)^{\frac{1}{\gamma}} & \text { if } \quad \frac{1}{2^{\gamma}} \leq \frac{(\alpha-c) n^{\gamma}}{\beta}<\frac{1+\gamma}{2^{\gamma}} \\
0 & \text { if } \left.\quad \frac{(\alpha-c) n^{\gamma}}{\beta} \geq \frac{1+\gamma}{2^{\gamma} \gamma}\right) \frac{\beta}{(\alpha-c) n^{\gamma}}
\end{array}\right.
$$

where $\gamma=1,2$. Notice that the first two lines (3.1) refer to local monopolistic equilib- 


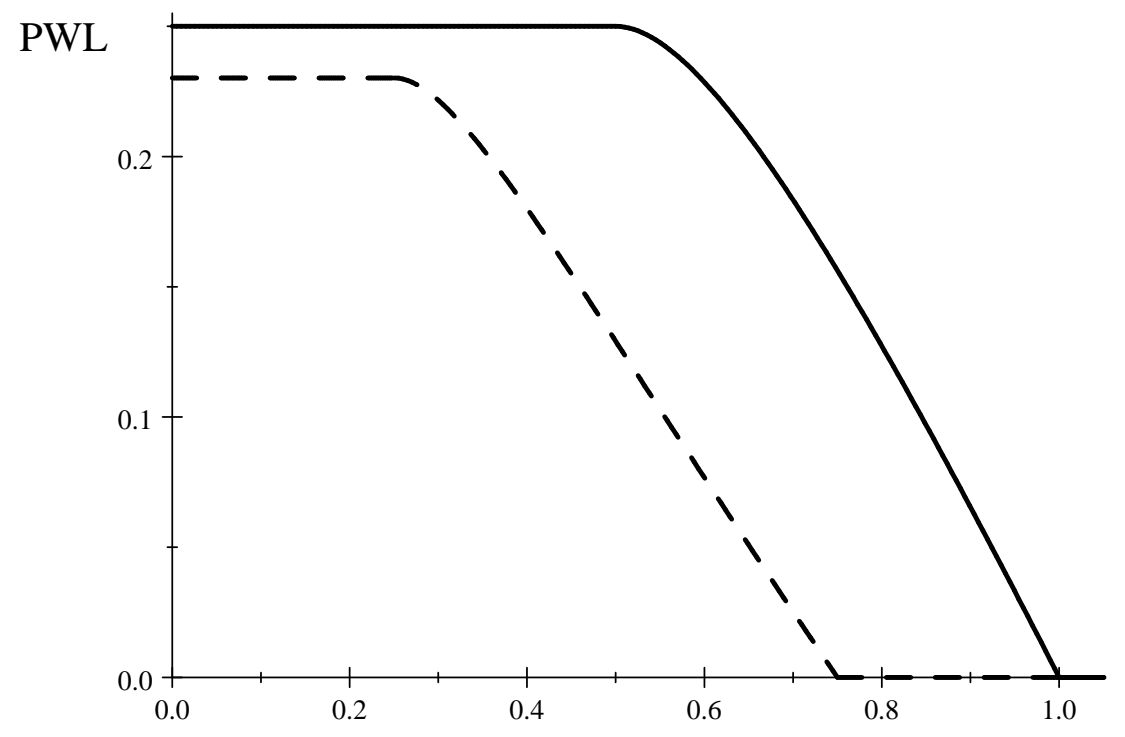

Figure 3.1: $P W L$ as a function of $\frac{(\alpha-c) n^{\gamma}}{\beta}$ for linear $\gamma=1$ (solid) and quadratic $\gamma=2$ (dash) transportation costs.

rium. The first (resp. second) line refers to the case in which the market should not (resp. should) be covered in the optimum. The last line refers to kinked and competitive equilibria. Since in the Salop model firms are located optimally and the price just transfers money from consumers to producers, positive welfare losses are only possible when the market is not covered. Figure 3.1 depicts $P W L$ as a function of $\frac{(\alpha-c) n^{\gamma}}{\beta}$ for linear $\gamma=1$ (solid) and quadratic $\gamma=2$ (dash) transportation costs.

We now study the relationship between the observable variables and $P W L$. As before, we assume that market price, outputs, marginal costs, number of active firms and $\gamma$ can be observed (in the Hotelling model we assumed that $\gamma=2$ ). Our view is that $\gamma$ reflects, basically, the technology of transportation and that this technology is common knowledge.

Formally, let $\{\mathfrak{p}, \mathfrak{x}, \mathfrak{c}, \mathfrak{n}, \gamma\}$ be an Observation, where $\mathfrak{p}(>\mathfrak{c})$ stands for market price, $\mathfrak{x}$ is quantity sold by each firm, which is defined as a proportion of consumers purchasing from each firm, $\mathfrak{c}$ is marginal cost, $\mathfrak{n} \in \mathbb{N}$ is the number of active firms and $\gamma \in\{1,2\}$ is 
the transportation costs. Then, we have the following result.

Proposition 2. Given an observation $\{\mathfrak{p}, \mathfrak{x}, \mathfrak{c}, \mathfrak{n}, \gamma\}$ there is a Circular Market $\{\alpha, \beta, \mathfrak{c}, \mathfrak{n}, \gamma\}$ such that $\{\mathfrak{p}, \mathfrak{x}\}$ is a Local Monopolistic Equilibrium for this market when not all the market is covered, i.e. when $\mathfrak{x n}<1$, and $P W L$ is given by

$$
P W L=\left\{\begin{array}{lll}
1-\frac{2+\gamma}{(1+\gamma)^{1+\frac{1}{\gamma}}} & \text { if } & \mathfrak{x n}<\frac{1}{(1+\gamma)^{\frac{1}{\gamma}}} \\
1-\frac{\gamma(2+\gamma) \mathfrak{n}}{(1+\gamma)^{2}-\frac{1}{(\mathfrak{x n})^{\gamma}}} & \text { if } & \frac{1}{(1+\gamma)^{\frac{1}{\gamma}}} \leq \mathfrak{n} \mathfrak{n}<1 \\
0 & \text { if } & \mathfrak{x n}=1
\end{array}\right.
$$

Proof: When $\mathfrak{x}<\frac{1}{\mathfrak{n}}$ (that is, not all the market is covered), let $\alpha=\frac{(1+\gamma) \mathfrak{p}-\mathfrak{c}}{\gamma}$ and $\beta=\frac{2^{\gamma}}{\gamma} \frac{\mathfrak{p}-\mathfrak{c}}{\mathfrak{x}^{\gamma}}$. We easily see that the circular market $\{\alpha, \beta, \mathfrak{c}, \mathfrak{n}, \gamma\}$ yields a local monopolistic equilibrium where $p_{m}^{*}=\mathfrak{p}$ and $D_{i}\left(p_{m}^{*}\right)=\mathfrak{x}$. When $\mathfrak{x} \mathfrak{n} \geq \frac{1}{(1+\gamma)^{\frac{1}{\gamma}}}$ in the optimum the whole market should be covered. Plugging $\alpha=\frac{(1+\gamma) \mathfrak{p}-\mathfrak{c}}{\gamma}$ and $\beta=\frac{2^{\gamma}}{\gamma} \frac{\mathfrak{p}-\mathfrak{c}}{\mathfrak{x}^{\gamma}}$ in (3.1) yields the formula (3.2) for $P W L$ as a function of observable market coverage $\mathfrak{x n}$ and transportation costs $\gamma$.

Figure 3.2 depicts $P W L$ as a function of observables $\mathfrak{x} \mathfrak{n}$ for linear (solid) and quadratic (dash) transportation costs. As in the Hotelling model, $P W L$ decreases with market coverage, unless in the optimum the whole market should not be covered; in this case $P W L$ is constant $(25 \%$ under linear transportation costs, as in the standard monopoly model with linear demand). When the whole market is covered both in equilibrium and in the optimum, there are no welfare losses since, as we mentioned above, social welfare does depend on the market coverage and not on prices. Other points are worth discussion.

Firstly, $P W L$ can be calculated in all cases. The indeterminacy that occurred in the Hotelling model does not arise here.

Secondly, as in the Hotelling model and for the same reason, $P W L$ is independent of demand elasticities and markups.

Thirdly, since here there are no misallocations due to wrong locations, $P W L$ is smaller than in the Hotelling model. But these losses may be large. 


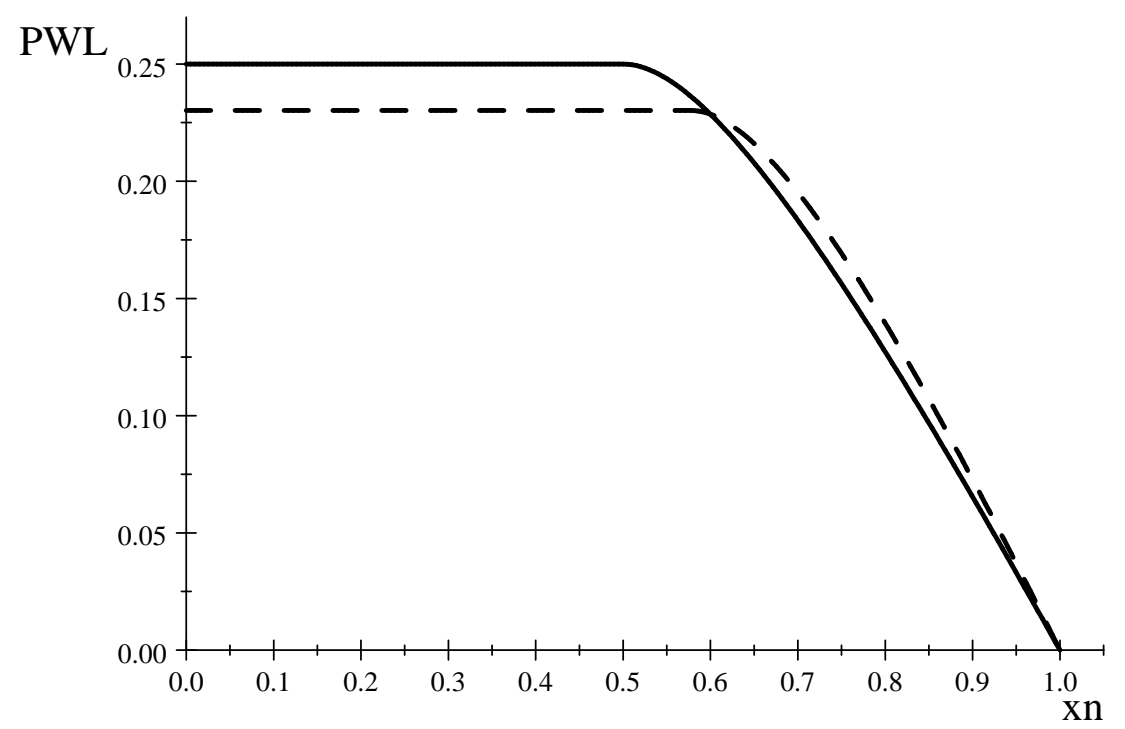

Figure 3.2: $P W L$ as a function of market coverage $\mathfrak{x n}$ for linear (solid) and quadratic (dash) transportation costs.

Finally, Figure 3.2 shows that $P W L$ is not monotonic in $\gamma$ for given market coverage. The reason is that a change in $\gamma$ changes welfare both in equilibrium and in the optimal allocations.

Entry can be considered in this framework by assuming that each firm incurs a fixed cost of entry, $K{ }^{15}$ In this case $P W L$ is a (non-monotonic) function of $\frac{\alpha-c}{\sqrt{\beta K}}$. $P W L$ can be very large, up to $50 \%$. Given an observation, there is a Circular Market with free entry such that the observation is an equilibrium for this market, and $P W L \in\left(0, \frac{1}{2}\right]$. Thus, the introduction of fixed costs makes it impossible to infer welfare losses from observations. As before, knowledge of the demand elasticity or the cross elasticity of demand adds nothing. All these results agree with those obtained in Corchón (2008) for the case of Cournot equilibrium with free entry and product homogeneity.

\footnotetext{
${ }^{15}$ The results reported in this paragraph are available upon request.
} 


\section{Vertical Differentiation}

In this section we study oligopolistic competition under quality differentiation. This model was developed by Gabszewicz and Thisse $(1979,1980)$ and Shaked and Sutton (1982, 1983). We consider the simplified version of Shaked and Sutton (1982). Again we have a two-stage game in which in the first stage firms compete in quality (one per firm) and in the second stage they compete in prices.

Consumers' preferences are described by $U=t s-p$ if the consumer purchases one unit of quality $s$ at price $p$, and by 0 otherwise. The parameter $t$ of taste for quality is uniformly distributed across the population of consumers, $t \sim U[a, b]$ with $0<a<b$. The density is $\frac{1}{b-a}$.

Assume that there are two firms in the market. Firm $i=1,2$ produces a good of quality $s_{i}$, where without loss of generality $s_{2}>s_{1}$. Suppose further that $s_{i}$ must belong to $(0, S]$. We assume zero costs. In particular, the choice of quality is costless.

Definition 9. A Linear Vertical Market is a list $\{a, b, S\}$ with $b>a>0$ and $S>0$.

Consider price competition. Consumers with high taste for quality buy the highquality good and consumers with lower taste for quality buy the low-quality good (which must be priced lower to attract any consumer), while consumers with the lowest taste for quality might not purchase at all. A consumer with taste parameter $t_{1}$ is indifferent between purchasing from firm 1 and not purchasing the differentiated commodity if and only if $t_{1} s_{1}-p_{1}=0$, so $t_{1}=\frac{p_{1}}{s_{1}}$. A consumer with taste parameter $t_{2}$ is indifferent between the two brands if and only if $t_{2} s_{1}-p_{1}=t_{2} s_{2}-p_{2}$, so $t_{2}=\frac{p_{2}-p_{1}}{s_{2}-s_{1}}$. Therefore, the demand functions read

$$
\begin{aligned}
& D_{1}=\frac{1}{b-a}\left(t_{2}-\max \left\{a, t_{1}\right\}\right)=\frac{1}{b-a}\left(\frac{p_{2}-p_{1}}{s_{2}-s_{1}}-\max \left\{a, \frac{p_{1}}{s_{1}}\right\}\right) \\
& D_{2}=\frac{1}{b-a}\left(b-t_{2}\right)=\frac{1}{b-a}\left(b-\frac{p_{2}-p_{1}}{s_{2}-s_{1}}\right)
\end{aligned}
$$

Each firm $i$ maximizes its profit $\pi_{i}=p_{i} D_{i}\left(p_{i}, p_{j}\right)$ with respect to $p_{i}$. We consider two possible cases in turn: where the market is not covered (i.e. $t_{1}>a$ ) and where the market is covered (i.e. $t_{1} \leq a$ ). 
Case where the market is not covered. When $t_{1}>a$, some consumers with low taste for quality purchase neither good. Firms' profit maximization yields

$$
p_{1}=\frac{b s_{1}\left(s_{2}-s_{1}\right)}{4 s_{2}-s_{1}} \text { and } p_{2}=\frac{2 b s_{2}\left(s_{2}-s_{1}\right)}{4 s_{2}-s_{1}}
$$

Then profits read

$$
\pi_{1}=\frac{b^{2} s_{1} s_{2}\left(s_{2}-s_{1}\right)}{(b-a)\left(4 s_{2}-s_{1}\right)^{2}} \text { and } \pi_{2}=\frac{4 b^{2} s_{2}^{2}\left(s_{2}-s_{1}\right)}{(b-a)\left(4 s_{2}-s_{1}\right)^{2}}
$$

The condition $t_{1}>a$ amounts to $0<s_{1}<\frac{b-4 a}{b-a} s_{2}$ for $b \geq 4 a$.

Case where the market is covered. When $t_{1} \leq a$, the market is covered and the consumer with the lowest taste parameter weakly prefers to purchase product 1. Firms' profit maximization yields

$$
p_{1}=\frac{1}{3}\left(s_{2}-s_{1}\right)(b-2 a) \text { and } p_{2}=\frac{1}{3}\left(s_{2}-s_{1}\right)(2 b-a),
$$

where $b>2 a$ (for both firms compete for consumers). Then profits read

$$
\pi_{1}=\frac{(b-2 a)^{2}\left(s_{2}-s_{1}\right)}{9(b-a)} \text { and } \pi_{2}=\frac{(2 b-a)^{2}\left(s_{2}-s_{1}\right)}{9(b-a)}
$$

Thus, the high-quality firm charges a higher price than the low-quality producer. It also makes a higher profit. For the whole market to be covered in equilibrium, the consumer with taste parameter $a$ should weakly prefer a low-quality good to nothing, i.e. $a s_{1}-p_{1} \geq 0$, which amounts to $\frac{b-2 a}{a+b} s_{2} \leq s_{1}<s_{2}$ for $b>2 a$.

Summing up the results of price competition, if $2 a<b<4 a$ an equilibrium arises where the entire market is covered. If $b \geq 4 a$ the market might be not covered and two types of equilibria arise: an equilibrium with an uncovered market for $0<s_{1}<\frac{b-4 a}{b-a} s_{2}$ and an equilibrium with a covered market for $\frac{b-2 a}{a+b} s_{2} \leq s_{1}<s_{2}$.

In the first stage, each firm $i$ maximizes $\pi_{i}\left(s_{i}, s_{j}\right)$ over $s_{i}$. The "marginal relocation tendency" of firm 2 reads $\frac{\partial \pi_{2}}{\partial s_{2}} \geq 0$ for all $s_{1}$ and $b>2 a$, therefore firm 2 chooses the maximal quality level $s_{2}^{*}=S$. Firm 1's profit maximization yields

$$
s_{1}^{*}= \begin{cases}\frac{b-2 a}{a+b} S & \text { if } \quad 2 a<b \leq 8 a \\ \frac{4}{7} S & \text { if } \quad b>8 a\end{cases}
$$




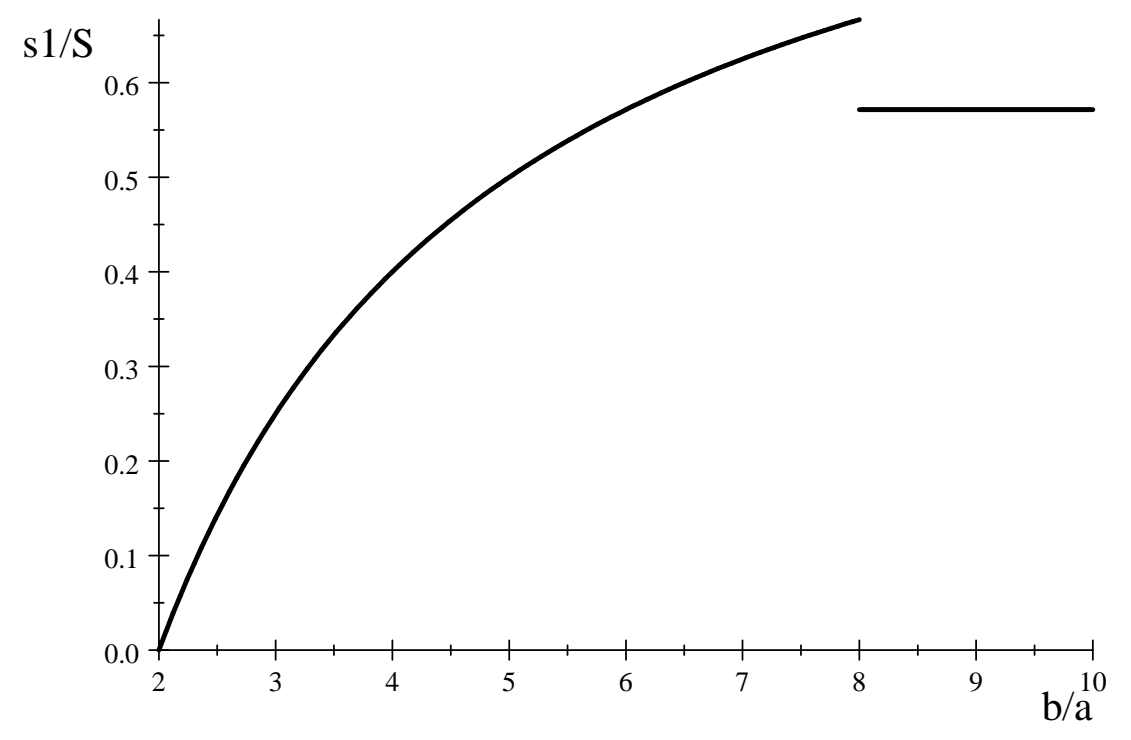

Figure 4.1: $\frac{s_{1}^{*}}{S}$ as a function of $\frac{b}{a}>2$.

Figure 4.1 depicts $\frac{s_{1}^{*}}{S}$ as a function of the market size $\frac{b}{a}$. Note that for $2<\frac{b}{a} \leq 8$ the entire market is covered, and the consumer with the lowest taste parameter $a$ is indifferent between buying the low quality product and neither product. The larger the market, the higher the quality of good 1 . The reason is that price competition between two goods drives their prices down to a level at which not even the consumer with the lowest taste for quality would want to buy good 1 if its quality is very low. So to attract consumers, firm 1 has to raise the quality of its good. At some point however-at $\frac{b}{a}=8$ exactly-firm 1 prefers to freeze the quality at constant level $s_{1}^{*}=\frac{4}{7} S$ and not to serve consumers with low taste parameters such that the market becomes uncovered. Thus, the discontinuity arises at the point in which the market becomes uncovered.

Definition 10. An equilibrium in the linear vertical market $\{a, b, S\}$ with $b>2 a$ is a list of qualities $\left\{s_{1}^{*}, s_{2}^{*}\right\}$, a list of prices $\left\{p_{1}^{*}, p_{2}^{*}\right\}$ and the percentage of market coverage 
$m^{*}$ such that

$$
\left\{s_{1}^{*}, s_{2}^{*}, p_{1}^{*}, p_{2}^{*}, m^{*}\right\}= \begin{cases}\left\{\frac{b-2 a}{a+b} S, S, \frac{a(b-2 a)}{a+b} S, \frac{a(2 b-a)}{a+b} S, 1\right\} & \text { if } \quad 2 a<b \leq 8 a \\ \left.\frac{4}{7} S, S, \frac{1}{14} S b, \frac{1}{4} S b, \frac{7 b}{8(b-a)}\right\} & \text { if } \quad b>8 a .\end{cases}
$$

Define social welfare, denoted by $W$, as the gross consumers' surplus:

$$
W=\int_{\max \left\{a, t_{1}\right\}}^{t_{2}} \frac{s_{1} t}{b-a} d t+\int_{t_{2}}^{b} \frac{s_{2} t}{b-a} d t
$$

which in the equilibrium reads

$$
W^{*}= \begin{cases}\frac{\left(5 a^{3}-5 a^{2} b+2 a b^{2}+3 b^{3}\right)}{6\left(b^{2}-a^{2}\right)} S & \text { if } \quad 2 a<b \leq 8 a \\ \frac{11 b^{2}}{24(b-a)} S & \text { if } \quad b>8 a .\end{cases}
$$

A social planner would choose the brands' quality to maximize the social welfare, thus $s_{1}^{o}=s_{2}^{o}=S$. Hence, in the optimal allocation there are two undifferentiated firms that make no profit, and the social welfare reads

$$
W^{o}=\frac{(a+b)}{2} S .
$$

Consequently, the percentage of welfare losses reads

$$
P W L=1-\frac{W^{*}}{W^{o}}=\left\{\begin{array}{lll}
\frac{\left(\frac{b}{a}-2\right)\left(4+\frac{b}{a}\right)}{3\left(\frac{b}{a}-1\right)\left(1+\frac{b}{a}\right)^{2}} & \text { if } & 2<\frac{b}{a} \leq 8 \\
\frac{\left(\frac{b}{a}\right)^{2}-12}{12\left(\frac{b}{a}-1\right)\left(\frac{b}{a}+1\right)} & \text { if } & \frac{b}{a}>8 .
\end{array}\right.
$$

Figure 4.2 depicts $P W L$ as a function of $\frac{b}{a}$. Notice that welfare losses are not large, with a maximum of about $8.33 \%$ (which is reached for very large markets, i.e., for $\frac{b}{a} \rightarrow \infty$ ). The $P W L$ is discontinuous with the market size $\frac{b}{a}$ since firm 1's quality is discontinuous with $\frac{b}{a}$ in equilibrium.

We are interested in $P W L$ yielded by this market, conditional on the values taken by certain variables that can be observed, namely market prices and market coverage. Formally:

Definition 11. An observation is a list $\left\{\mathfrak{p}_{1}, \mathfrak{p}_{2}, \mathfrak{m}\right\}$ where $\mathfrak{p}_{1}>0$ is low-quality good price, $\mathfrak{p}_{2}>\mathfrak{p}_{1}$ is high-quality good price and $\mathfrak{m} \in[0,1]$ is the percentage of market coverage. 


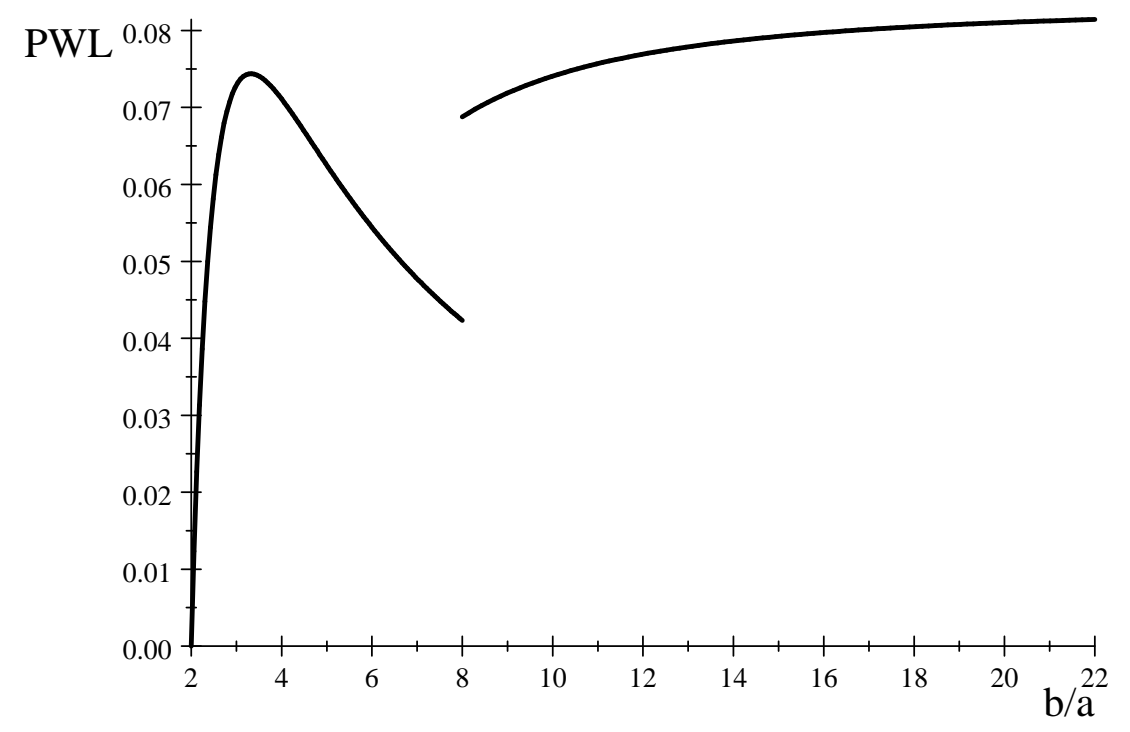

Figure 4.2: $P W L$ as a function of $\frac{b}{a}>2$.

Let us relate $P W L$ with observable variables.

Proposition 3. i) Given an observation $\left\{\mathfrak{p}_{1}, \mathfrak{p}_{2}, \mathfrak{m}\right\}$ where $\mathfrak{m}=1$ and $0<\frac{\mathfrak{p}_{1}}{\mathfrak{p}_{2}} \leq \frac{2}{5}$, there is a linear vertical market $\{a, b, S\}$ such that $\left\{S \frac{\mathfrak{p}_{1}}{\mathfrak{p}_{2}-\mathfrak{p}_{1}}, S, \mathfrak{p}_{1}, \mathfrak{p}_{2}, \mathfrak{m}\right\}$ is an equilibrium for this market, and

$$
P W L=\frac{\frac{\mathfrak{p}_{1}}{\mathfrak{p}_{2}}\left(6\left(\frac{\mathfrak{p}_{1}}{\mathfrak{p}_{2}}\right)^{2}-7 \frac{\mathfrak{p}_{1}}{\mathfrak{p}_{2}}+2\right)}{3\left(1-\frac{\mathfrak{p}_{1}}{\mathfrak{p}_{2}}\right)^{2}\left(\frac{\mathfrak{p}_{1}}{\mathfrak{p}_{2}}+1\right)}
$$

ii) Given an observation $\left\{\mathfrak{p}_{1}, \mathfrak{p}_{2}, \mathfrak{m}\right\}$ where $\frac{7}{8}<\mathfrak{m}<1$, and $\frac{\mathfrak{p}_{1}}{\mathfrak{p}_{2}}=\frac{2}{7}$, there is a linear vertical market $\{a, b, S\}$ such that $\left\{\frac{4}{7} S, S, \mathfrak{p}_{1}, \mathfrak{p}_{2}, \mathfrak{m}\right\}$ is an equilibrium for this market, and

$$
P W L=\frac{\left(\frac{8 \mathfrak{m}}{8 \mathfrak{m}-7}\right)^{2}-12}{12\left(\frac{8 \mathfrak{m}}{8 \mathfrak{m}-7}-1\right)\left(\frac{8 \mathfrak{m}}{8 \mathfrak{m}-7}+1\right)}
$$

Proof: First, consider the case where the entire market is covered, $\mathfrak{m}=1$, and 
$0<\frac{\mathfrak{p}_{1}}{\mathfrak{p}_{2}} \leq \frac{2}{5}$. Let us fix $S>0$ and let

$$
\mathfrak{p}_{1}=\frac{a(b-2 a)}{a+b} S, \mathfrak{p}_{2}=\frac{a(2 b-a)}{a+b} S
$$

which yields

$$
a=\frac{\mathfrak{p}_{2}-\mathfrak{p}_{1}}{S}, b=\frac{\left(2 \mathfrak{p}_{2}-\mathfrak{p}_{1}\right)\left(\mathfrak{p}_{2}-\mathfrak{p}_{1}\right)}{\left(\mathfrak{p}_{2}-2 \mathfrak{p}_{1}\right) S}
$$

It is straightforward to check that $2<\frac{b}{a} \leq 8$ since $0<\frac{\mathfrak{p}_{1}}{\mathfrak{p}_{2}} \leq \frac{2}{5}$. Then by construction the market $\{a, b, S\}$ yields an equilibrium where $\left\{s_{1}^{*}, s_{2}^{*}, p_{1}^{*}, p_{2}^{*}, m^{*}\right\}=\left\{S \frac{\mathfrak{p}_{1}}{\mathfrak{p}_{2}-\mathfrak{p}_{1}}, S, \mathfrak{p}_{1}, \mathfrak{p}_{2}, \mathfrak{m}\right\}$. Plugging $a=\frac{\mathfrak{p}_{2}-\mathfrak{p}_{1}}{S}$ and $b=\frac{\left(2 \mathfrak{p}_{2}-\mathfrak{p}_{1}\right)\left(\mathfrak{p}_{2}-\mathfrak{p}_{1}\right)}{\left(\mathfrak{p}_{2}-2 \mathfrak{p}_{1}\right) S}$ into the first line of (4.1) we get (4.2) for $P W L$ as a function of an observation $\left\{\mathfrak{p}_{1}, \mathfrak{p}_{2}, \mathfrak{m}\right\}$.

Second, consider the case where the market is not covered, $\frac{7}{8}<\mathfrak{m}<1$, and $\frac{\mathfrak{p}_{1}}{\mathfrak{p}_{2}}=\frac{2}{7}$. Fix $S>0, a>0$ and let

$$
\mathfrak{p}_{1}=\frac{1}{14} S b, \mathfrak{p}_{2}=\frac{1}{4} S b \text { and } \mathfrak{m}=\frac{7 b}{8(b-a)},
$$

which yields

$$
b=\frac{8 \mathfrak{m}}{8 \mathfrak{m}-7} a .
$$

One can easily check that $\frac{b}{a}>8$ for $\frac{7}{8}<\mathfrak{m}<1$. Then by construction the market $\{a, b, S\}$ yields an equilibrium where $\left\{s_{1}^{*}, s_{2}^{*}, p_{1}^{*}, p_{2}^{*}, m^{*}\right\}=\left\{\frac{4}{7} S, S, \mathfrak{p}_{1}, \mathfrak{p}_{2}, \mathfrak{m}\right\}$. Plugging $\frac{b}{a}=\frac{8 \mathfrak{m}}{8 \mathfrak{m}-7}$ into the second line of (4.1) yields (4.3) for $P W L$ as a function of observables.

Figure 4.3 depicts $P W L$ as a function of $\frac{\mathfrak{p}_{1}}{\mathfrak{p}_{2}}$ for $\mathfrak{m}=1$ and $0<\frac{\mathfrak{p}_{1}}{\mathfrak{p}_{2}} \leq \frac{2}{5} . P W L$ is easily seen to be single-peaked in the domain $\left(0, \frac{2}{5}\right]$ reaching a maximum at, approximately, $\frac{\mathfrak{p}_{1}}{\mathfrak{p}_{2}}=0.23$. Thus, an increase in relative prices can decrease or increase relative welfare losses. Figure 4.4 depicts $P W L$ as a function of $\mathfrak{m}$ for $\frac{7}{8}<\mathfrak{m}<1$ and $\frac{\mathfrak{p}_{1}}{\mathfrak{p}_{2}}=\frac{2}{7}$. Here $P W L$ depends only on the market coverage, in a decreasing way, as expected.

\section{Conclusion}

In this paper we have studied welfare losses in models of horizontal (i.e. location) and vertical (i.e. quality) differentiation. Here is a summary of our main results. 


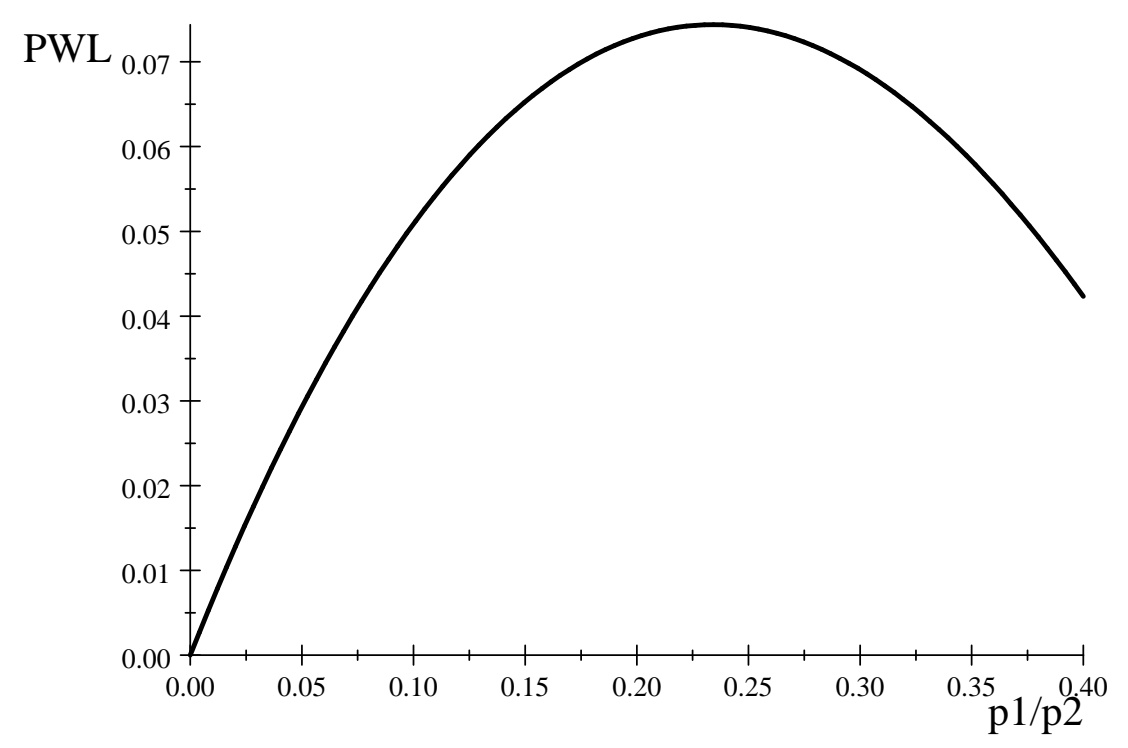

Figure 4.3: $P W L$ as a function of $\frac{\mathfrak{p}_{1}}{\mathfrak{p}_{2}}$ for $\mathfrak{m}=1$ and $0<\frac{\mathfrak{p}_{1}}{\mathfrak{p}_{2}} \leq \frac{2}{5}$.

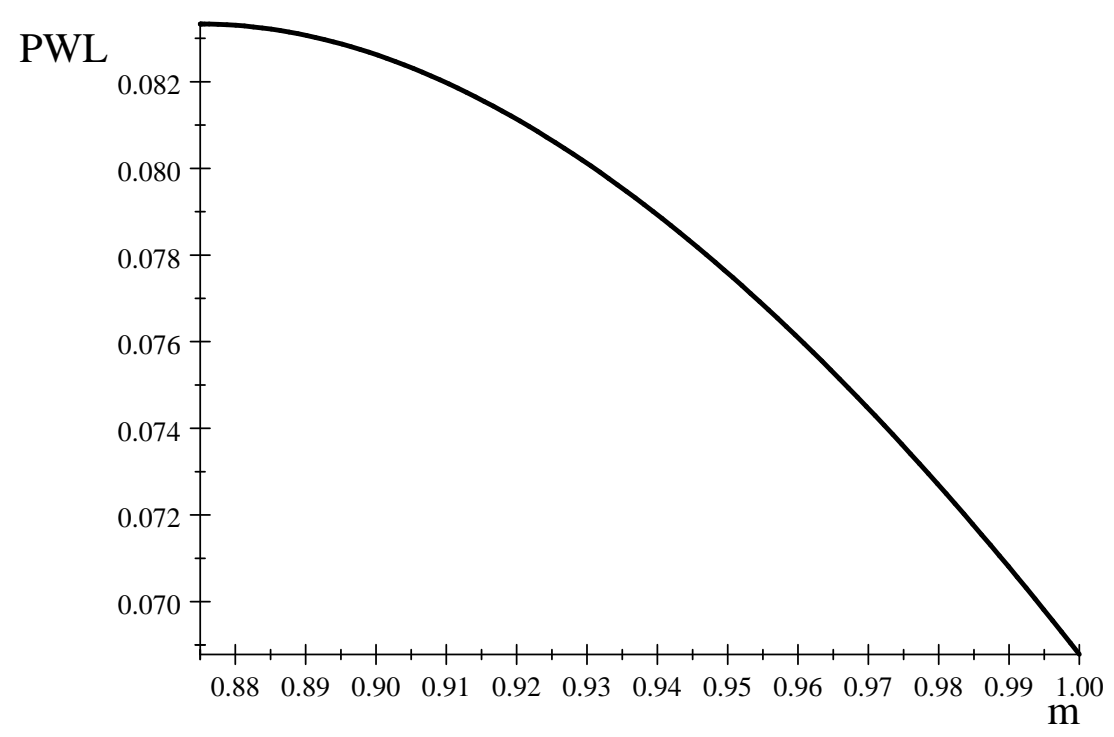

Figure 4.4: $P W L$ as a function of $\mathfrak{m}$ for $\frac{7}{8}<\mathfrak{m}<1$ and $\frac{\mathfrak{p}_{1}}{\mathfrak{p}_{2}}=\frac{2}{7}$. 
1. In location models, despite price competition, welfare losses can be very large, larger than under monopoly with similar demand but no location choice, the latter being $25 \% .^{16}$ Except in a single case, welfare losses can be inferred from observables. Welfare losses are due to lack of market cover and to firms located in the wrong positions. Markups and demand elasticities do not play any role in determining welfare losses in these models. They might play a role if consumers were allowed to buy several goods.

2. Under vertical differentiation welfare losses can be read from prices and market coverage but they are discontinuous with the size of the market. The percentage of welfare losses here is not very large. Thus, despite the apparent similarities in the derivation of equilibrium in models of horizontal and vertical differentiation, these two models are very different from the point of view of welfare losses.

The main conclusion of our paper is that the emphasis in empirical studies of oligopolistic welfare losses and the theory of regulation on prices or outputs might be a little misguided. Our analysis of horizontal differentiation models suggests that variables like location or market coverage play a relevant role. In contrast, there is some work on quality regulation (see Armstrong and Sappington 2005 for an excellent survey of regulation) but our analysis suggests that welfare losses arising from such an item in oligopolistic markets might be not very large.

Several extensions of our work are worth mentioning. The models considered in this paper are symmetric, assume two firms only (except in the case of the Salop model) and rely on specific forms of the commodity space. We hope that our methods can be used to study models with asymmetric firms, see e.g. Aghion and Schankerman (2004) for a Salop model with heterogeneous costs or with other forms of the commodity space such as the Spokes model, Chen and Riordan (2007). Another possible extension of our work would be to study consumer and producer surpluses separately and see the effects of location and market coverage on each variable.

\footnotetext{
${ }^{16}$ This follows from Proposition 6 in Anderson and Renault (2003) by setting $n=\rho=1$.
} 


\section{References}

[1] Aghion, P. and Schankerman, M. (2004). "On the Welfare Effects and Political Economy of Competition-Enhancing Policies." The Economic Journal, 114, 800824.

[2] Anderson, S.P. and Renault, R. (2003). "Efficiency and Surplus Bounds in Cournot Competition." Journal of Economic Theory, 113, 253-264.

[3] Armstrong, M. and Sappington, D. (2005). "Recent Developments in the Theory of Regulation". Forthcoming in the Handbook of Industrial Organization, Vol. III, edited by M. Armstrong and R. Porter.

[4] Becker, G., DeGroot, M. and Marschak, J. (1964). "Measuring Utility by a Singleresponse Sequential Method." Behavioral Science, 9, 226-236.

[5] Chen, Y. and Riordan, M. H. (2007). "Price and Variety in the Spokes Model." The Economic Journal, 117, 897-921.

[6] Corchón, L. (2008). "Welfare Losses under Cournot Competition." International Journal of Industrial Organization, 26, 1120-1131.

[7] Corchón, L. and Zudenkova, G. (2009). "Computing Welfare Losses from Data under Imperfect Competition with Heterogeneous Goods." International Journal of Industrial Organization, 27, 646-654.

[8] Cowling, K. and Mueller, D.C. (1978). "The Social Costs of Monopoly Power." Economic Journal, 88, 727-748.

[9] D’Aspremont, C., Gabszewicz, J. J. and Thisse, J.-F. (1979). "On Hotelling's Stability in Competition." Econometrica, 47, 1145-1150.

[10] Economides, N. (1984). "The Principle of Minimum Differentiation Revisited." European Economic Review, 24, 345-368.

[11] Economides, N. (1986). "Minimal and Maximal Product Differentiation in Hotelling's Duopoly." Economics Letters, 21, 67-71. 
[12] Economides, N. (1989). "Symmetric Equilibrium Existence and Optimality in Differentiated Product Markets." Journal of Economic Theory, 47, 178-194.

[13] Fan, Y. (2010). "Ownership Consolidation and Product Quality: A Study of the U.S. Daily Newspaper Market." Mimeo, University of Michigan.

[14] Gabszewicz, J. J. and Thisse, J.-F. (1979). "Price Competition, Quality and Income Disparities." Journal of Economic Theory, 20, 340-359.

[15] Gabszewicz, J. J. and Thisse, J.-F. (1980). "Entry (and Exit) in a Differentiated Industry." Journal of Economic Theory, 22, 327-338.

[16] Harberger, A. C. (1954): "Monopoly and Resource Allocation." American Economic Review: Papers and Proceedings. 44, 77-87.

[17] Horowitz, J. (2006). "The Becker-DeGroot-Marschak Mechanism is not Necessarily Incentive Compatible, even for Non-random Goods." Economics Letters, 93, 6-11.

[18] Hotelling, H. (1929). "Stability in Competition." Economic Journal, 39, 41-57.

[19] Leibenstein, H. (1966). "Allocative Efficiency versus X-Efficiency." American Economic Review, 56, 392-425.

[20] Salop, S. C. (1979). "Monopolistic Competition with Outside Goods." Bell Journal of Economics, 10, 141-156.

[21] Shaked, A. and Sutton, J. (1982). "Relaxing Price Competition through Product Differentiation." Review of Economic Studies, 49, 3-13.

[22] Shaked, A. and Sutton, J. (1983). "Natural Oligopolies." Econometrica, 51, 14691483.

[23] Tullock, G. (1967). "The Welfare Costs of Tariffs, Monopolies, and Theft." Western Economic Journal, 5, 224-232. 